\title{
MODERN PUBLIC SERVICE ADVERTISING IN RUSSIA AND THE UNITED STATES: TOPICS AND FUNCTIONAL SPECIFICITY
}

\author{
Svetlana A. Chubay \\ Volgograd State University, Volgograd, Russia
}

\begin{abstract}
On the basis of scientific publications of Russian and American researchers the author reveals content and functional features of modern public service announcements and ads in the USA and Russia, offers a definition of the public service announcement as a form of advertising communication, identifies its general and special functions (educational and intellectual), distinguishes a set of motivations that explains the targeting factors. Dominant parameters of public interest announcements and ads, the role of the state in their production, the channels of their distribution that might raise the amount of mass addressees, efficiency of socially important content delivery as well as public acceptance patterns are in the focus of attention. The author's observations and analysis of social advertising posters in the USA and Russia are presented as a set of topics that reflects the involvement of both countries in the global issues discussions and national peculiarities in their consideration. The conclusion states correlation between topical content and extralinguistic factors which explains qualitative differences between public service announcements and ads in the USA and Russia.

Key words: public service advertising, advertising message, advertising text, non-commercial advertising, public announcement.

Citation. Chubay S.A. Modern Public Service Advertising in Russia and the United States: Topics and Functional Specificity. Vestnik Volgogradskogo gosudarstvennogo universiteta. Seriya 2, Yazykoznanie [Science Journal of Volgograd State University. Linguistics], 2017, vol. 16, no. 4, pp. 201-206. (in Russian). DOI: https:// doi.org/10.15688/jvolsu2.2017.4.19
\end{abstract}

УДК 81 ' $42: 659.181$

Дата поступления статьи: 27.09.2017

ББК 81.055 .516

Дата принятия статьи: 24.11.2017

\section{СОВРЕМЕННАЯ СОЦИАЛЬНАЯ РЕКЛАМА В РОССИИ И США: ТЕМАТИКА И ОСОБЕННОСТИ ФУНКЦИОНИРОВАНИЯ}

\author{
Светлана Анатольевна Чубай \\ Волгоградский государственный университет, г. Волгоград, Россия
}

\begin{abstract}
Аннотация. Автор на основе анализа научных публикаций российских и американских исследователей выявляет особенности содержания и функционирования современной социальной рекламы в США и России. Характеризуются сходства и различия терминологического определения социальной рекламы как вида рекламной коммуникации, универсальные и специфические функции (воспитательная и просветительская), выполняемые социальной рекламой, и цели, на достижение которых она направлена. Устанавливаются особенности реализации таких ключевых параметров социальной рекламы, как участие государ- ства в создании и продвижении рекламного продукта социальной тематики; возможности использования разнообразных каналов распространения социальной рекламы, обеспечивающих массовость адресата; ¿ эффективность речевого воплощения социального содержания; восприимчивость общества к социаль$\smile$ ной рекламе. С привлечением результатов авторских наблюдений над социальным плакатом рассмотрены особенности тематики социальной рекламы в России и США, показана их общность, отражающая вовлеченность обеих стран в решение общемировых проблем, и различия, отражающие наиболее значимые (2) ценности каждого социума. В результате систематизации научной литературы автор приходит к выводу о
\end{abstract}


том, что качественные различия социальной рекламы в США и России обусловлены экстралингвистическими причинами.

Ключевые слова: социальная реклама, рекламная идея, рекламный текст, некоммерческая реклама, общественная реклама.

Цитирование. Чубай С. А. Современная социальная реклама в России и США: тематика и особенности функционирования // Вестник Волгоградского государственного университета. Серия 2, Языкознание. - 2017. T. 16, № 4. - C. 201-206. - DOI: https://doi.org/10.15688/jvolsu2.2017.4.19

\section{1}

Реклама сегодня выполняет множество функций и уже является не только элементом экономики и торговли, но и политики, общества в целом [см. подробнее: Барябин, 2008; Воат, 2010; Гарфилд, 2015; Джонс, 2015; Марусева, 2016; Михеев, 2014; Ульяновский, 2016; Чубай, 2015], что получает отражение в развитии такого вида рекламы, как социальная реклама. Этот феномен уже стал объектом научных исследований. Однако, несмотря на достижения в изучении социальной рекламы, многие ее аспекты, как отмечается в ряде работ современных ученых, требуют гораздо более глубокого осмысления (см. подробнее: [Акулич, 2010; Измайлова, 2016; Степанов, 2007; Шелковникова, 2013]).

Так, в научной литературе по-разному определяется объем понятия «социальная реклама», а следовательно, предлагаются разные термины для ее обозначения. Независимо от разновидности рекламной коммуникации реклама создается с вполне конкретной целью оказать влияние на целевую аудиторию. При этом сегодня важны ее воспитательная, просветительская функции, которые обозначились в современном обществе в связи с актуализацией ряда проблем: загрязнение окружающей среды, проблема детей-сирот, неуважительное отношение к людям с ограниченными возможностями, курение, алкоголизм, наркомания, СПИД и т. д. Традиционно в российской науке рекламу, популяризирующую знания в этих областях, называют социальной; она необходима современному обществу, чтобы воспитать у граждан такие качества, как гуманизм, сострадание, толерантность.

В исследованиях европейских и американских ученых используются термины «некоммерческая реклама» и «общественная реклама» [Boorstin, 1994; Goodrum, Dalrymple, 2010].
Некоммерческая реклама - реклама, спонсируемая некоммерческими институтами или в их интересах и имеющая целью стимулирование пожертвований, призыв голосовать в чью-либо пользу или привлечение внимания к делам общества [Мандель, 2014, с. 176].

Общественная (социальная) реклама передает сообщение, пропагандирующее какое-либо позитивное явление. Профессионалы создают ее бесплатно (конкретнее говорить об этической позиции отказа от прибыли); место и время в СМИ также предоставляются на некоммерческой основе [Мандель, 2014 , с. 177]. Американскими учеными для обозначения такого вида рекламы были введены термины «Public service advertising» и «Public service announcement» (PSA). Предмет PSA - идея, обладающая некой социальной ценностью. Цель - изменение взглядов общества на какую-либо проблему, в перспективе создание новых социальных ценностей [Мандель, 2014, с. 177].

Представленные определения, отражая существенные признаки понятия, дают возможность убедиться в том, что и некоммерческая реклама, и общественная реклама, и PSA ставят перед собой единые цели, которые в работах современных российских исследователей связываются с понятием «социальная реклама». Наиболее полно универсальные цели социальной рекламы охарактеризованы в статье Г.Г. Николайшвили [2008]. К наиболее значимым из них он относит:

- информирование о предоставлении различных социальных услуг;

- формирование общественного мнения;

- привлечение внимания к назревшим социальным проблемам и призыв к действиям, направленным на их решение;

- пропаганда закрепления в обществе некоторых поведенческих установок;

- формирование положительного отношения к государственным структурам; 
- демонстрация социальной ответственности бизнеса;

- укрепление социально значимых институтов общества;

- формирование новых типов общественных отношений;

- изменение поведенческой модели общества.

\section{2}

Социальная реклама в разных странах, будучи направленной на достижение одних и тех же целей, решение одних и тех же задач, имеет существенные отличия, обусловленные многими причинами экстралингвистического характера.

Так, США имеют значительный опыт в сфере социальной рекламы, и, как показывают опубликованные исследования (см. подробнее: [Boorstin, 1994; Cultip, Center, Broom, 1997; Goodrum, Dalrymple, 2010]), активно развивают эту форму влияния на общество. Характеризуя современную социальную рекламу в США, ученые отмечают следующие ее особенности (см. подробнее: [Голуб, 2009; Михеев, 2014; Boorstin, 1994; Cravens, Hills, Woodruff, 2007]):

- главным заказчиком социальной рекламы выступает государство (теоретики социальной рекламы оценивают этот факт как правильное поведение правительства, которое осуществляет заботу о своем населении, об обществе в целом);

- для распространения социальной рекламы используются разнообразные каналы, с учетом фактора адресата;

- достижение эффективности за счет креативного воплощения, интересных образов, творческих слоганов;

- восприимчивость населения к социальной рекламе, которое готово менять свое отношение к определенной проблеме, свои поведенческие установки;

- содержание социальной рекламы главным образом сосредоточено на долге, обязанностях, ответственности людей за свои поступки; она в значительной мере опирается на императивную форму регулирования социальных отношений. Этические ценности и нормы, устанавливающие границы между добром и злом и находящие поддержку в правовом поле (в виде принципов соблюдения долга, уважения прав и достоинства человека, автономии другой личности, принципа справедливости, равного и одинакового обращения с людьми и т. п.) - основа такой рекламы [Goodrum, Dalrymple, 2010, p. 317].

\section{3}

В исследованиях, посвященных российской социальной рекламе, отмечается, что понятие социальной рекламы и его юридические характеристики представлены не вполне определенно [Ульяновский, 2014, с. 346]. Это обусловлено многими причинами, основными из которых ученые считают «молодость» понятия «социальная реклама» в России, размытость самого определения, недостаточное внимание к социальным проблемам со стороны общества и государства и недостаточное финансирование со стороны государства. В работах исследователей (см., например: [Голуб, 2009; Михеев, 2014] показано, что:

- государство эпизодически участвует в выделении средств и поддержке социальной рекламы, ее создание и размещение финансируется, как правило, коммерческими структурами. Расходы на такую рекламу они включают в свой годовой бюджет. Крупные компании все чаще учитывают социальные вопросы при разработке своих рекламных стратегий. Например, ассоциация менеджеров России инициировала «Социальную программу бизнеса». В ней участвуют такие компании, как «Аэрофлот», «Инреррос», «Данон Индустрия», «М-Видео», «Металлоинвест» и др.;

- для распространения социальной рекламы используются, как правило, СМИ, что не всегда связано с учетом фактора адресата;

- речевое воплощение содержания не всегда эффективно. Исследуя стилистические и прагмалингвистические особенности российских социально-рекламных текстов, Н.В. Мещерякова установила, что подавляющее большинство социально-рекламных текстов характеризуются афористичностью, нравственно-назидательной направленностью. При этом для социальной рекламы гораздо менее характерна яркая окказиональная образность 


\section{МАТЕРИАЛЫ И СООБЩЕНИЯ}

(новые, неожиданные метафоры, обороты речи). Социальная реклама по большей части использует уже устоявшиеся в общественном речевом узусе образные выражения. Оживление социальных образных штампов происходит за счет соотнесения вербальной части рекламного текста с невербальным визуальным компонентом. В социально-рекламных текстах широко используется опора на интертекстуальные ассоциации, то есть использование крылатых слов, выражений или афоризмов из кинофильмов, театральных постановок, песен, литературных произведений [Мещерякова, 2010, с. 212];

- население, согласно исследованию О.Ю. Голуб, в силу экономических условий жизни, озабочено удовлетворением насущных потребностей, поэтому глобальные вопросы экологии, культуры и т. д. находятся все поля интересов большинства граждан [Голуб, 2009, c. 56];

- содержание российской социальной рекламы в целом согласуется с актуальными общемировыми общественными проблемами.

Проведенное нами исследование тематики социальной рекламы на материале 50 социальных плакатов показало, что частотными темами социальной рекламы в современной России являются: $40 \%$;

1) алкоголизм, курение и наркомания -

2) профилактика чрезвычайных ситуаций и личной безопасности граждан (особенно часто направлена на безопасность дорожного движения) $-25 \%$;

3) насилие в семье - $18 \%$;

4) терроризм - $10 \%$;

5) гражданские права и обязанности $7 \%$.

Однако освещаются эти темы специфично, поэтому согласимся с О.Ю. Голуб, характеризующей особенности, присущие социальной рекламе в нашей стране:

- часто содержание рекламы направлено не на профилактику острой общественной проблемы, а на устранение ее последствий;

- предлагается очень малое количество способов решения проблемы, чаще всего один - сбор денежных средств;

- социальные компании, акции носят эпизодический, а не постоянный характер;
- узкая тематика в сравнении с другими странами;

- социальная реклама - мощный инструмент мобилизации общества для достижения конкретной цели;

- широко распространенная пропаганда;

- недостаточная освещенность внутренних проблем (голод, бедность, сироты) в противовес преувеличенному вниманию к проблемам мирового уровня [Голуб, 2009, с. 57].

Причины, обусловившие особенности социальной рекламы в России, имеют, как мы уже отмечали, экстралингвистический характер и связаны с недостаточным вниманием к социальным проблемам со стороны общества и государства и, следовательно, с недостаточным финансированием деятельности по созданию и продвижению рекламного продукта социальной направленности. Кроме того, в современной социальной рекламе в России, как отмечает Е.В. Степанов, очевидны отголоски ее прошлого. Ее нынешнее состояние отражает то, что долгое время в нашей стране основные темы социальной рекламы не касались конкретного человека, не были обращены к человеческим ценностям, а лишь несли в себе идеологию государства [Степанов, 2007, с. 27]. Однако данное явление претерпело значительные изменения. Процесс становления этой разновидности рекламной коммуникации в полной мере в нашей стране только начинается, опубликованные научные исследования подтверждают тот факт, что социальная реклама в России сегодня не только инструмент пропаганды политики государства, но и инструмент освещения общественных проблем и ценностей [Марусева, 2016, с. 147].

4

Анализ современных исследований, посвященных изучению тематики и основных проблем, связанных с содержанием и функционированием социальной рекламы в российском обществе, демонстрирует, что сегодня эта разновидность рекламной коммуникации в нашей стране качественно не оформлена. Эффективность социальной рекламы за рубежом выше, что обусловлено как историческими причинами, так и современным отношением к самому феномену социальной рекламы. 


\section{СПИСОК ЛИТЕРАТУРЫ}

Акулич К. В., 2010. Социальная реклама в современной России как социально-политическая проблема // Вестник философии и социологии Курского государственного университета. № 1. С. 213-215.

Барябин А. В., 2008. Социальные функции рекламы как феномена повседневной культурной коммуникации // Вестник Поволжской академии государственной службы. № 2 (15). C. $106-110$.

Воат А. А., 2010. Рекламно-информационное пространство в структуре информационного общества (социально-философский анализ) // Этносоциум и межнациональная культура. №6 (30). С. 198-204.

Гарфилд Б., 2015. Десять заповедей рекламы. М. : СПб. : Питер. $256 \mathrm{c.}$

Голуб О. Ю., 2009. Реклама, статусное потребление и стиль жизни // Потребление как коммуникация - 2009 : материалы V международной конференции (26-27 июня 2009 г.) / под ред. В.И. Ильина, В.В. Козловского. СПб. : Интерсоцис. С. 55-58.

Джонс Дж. Ф., 2015. Мифы, небылицы и факты о рекламе: анализ 28 самых живучих мифов. М. : Омега. 336 c.

Измайлова М. А., 2016. Психология рекламной деятельности. М. : Дашков и К․ 444 с.

Мандель Б. Р., 2014. Психология рекламы: попытка разобраться, или критика против полемики // Гуманитарные науки и образование в Сибири. № 6 (18). С. 175-180.

Марусева И. В., 2016. Мишень вкуса: аксиомы и структура арт-маркетинга; графический дизайн и креатив; рекламные арт-мемы; творческий метод создания рекламы «Золотое сечение». М. : Директ-Медиа. 305 с.

Мещерякова Н. В., 2010. Роль образных средств в создании текстов социальной рекламы // Ученые записки Российского государственного социального университета. № 9 (85). С. 211-214.

Михеев В. А., 2014. Основы социального партнерства: теория и политика. М. : Экзамен. 448 с.

Николайшвили Г. Г., 2008. Социальная реклама: некоторые вопросы теории и практики // Регионология. № 2. С. 263-275.

Степанов Е. В., 2007. Особенности языка и стиля социальной рекламы // Вестник Московского университета. Серия 10, Журналистика. № 4. С. 24-39.

Ульяновский А., 2014. Мифодизайн: коммерческие и социальные мифы. М. : СПб. : Питер. 544 с.

Ульяновский А., 2016. Мифодизайн рекламы. М. : СПб. : Петрополь. 300 с.
Чубай С. А., 2015. Ключевые признаки политической рекламы как самостоятельного вида рекламной коммуникации // Вестник Волгоградского государственного университета. Серия 2, Языкознание. Т. 14, № 3. С. 32-39. DOI: http://dx.doi.org/10.15688/jvolsu2.2015.3.16.

Шелковникова Х., 2013. Анализ и пуги совершенствования социальной рекламы в городе Кемерово. M. : LAP Lambert Academic Publishing. 108 c.

Boorstin D., 1994. Advertising and American Civilization // Advertising and Society. New York. C. 24-39.

Cravens D.W., Hills G.E., Woodruff R.B., 2007. Marketing Management. Homewood; Illinois : Irwin. 364 p.

Cultip S., Center A., Broom G., 1997. Effective public relations : 7th ed. New Jercy. 243 p.

Goodrum Ch., Dalrymple H., 2010. Advertising in America. The First 200 Years. N.Y. : Harry N. Abrams. 477 p.

\section{REFERENCES}

Akulich V.K., 2010. Social advertising in modern Russia as a socio-political problem. Vestnik filosofii $i$ sotsiologii Kurskogo gosudarstvennogo universiteta, no. 1, pp. 213-215. (in Russian).

Barybin A.V., 2008. Social function of advertising as a phenomenon of everyday cultural communication. Vestnik Povolzhskoy akademii gosudarstvennoy sluzhby [Bulletin of the Volga Region Academy for Civil Service], no. 2, pp. 106-110. (in Russian).

Voat A.A., 2010. Advertising and information space in the structure of the information society (sociophilosophical analysis). Etnosotsium $i$ mezhnatsionalnaya kultura, no. 6 (30), pp. 198204. (in Russian).

Garfild B., 2015. The Ten Commandments of Advertising. Moscow, St. Petersburg, Piter Publ. 256 p. (in Russian).

Golub O.Y., 2009. Advertising, status consumption and lifestyle. Ilyin V.I., Kozlovskiy V.V., eds. Potreblenie kak kommunikatsiya - 2009: Materialy V mezhdunarodnoy konferentsii. 2627 June 2009. Saint Petersburg, Intersotsis Publ., pp. 55-58. (in Russian).

Dzhons Dzh. F., 2015. Myths, fables and facts about advertising: analysis of the 28 most enduring myths. Moscow, Omega Publ. 336 p. (in Russian).

Izmaylova M.A., 2016. Psychology of advertising activities. Moscow, Dashkov i K ${ }^{\circ}$ Publ. 444 p. (in Russian).

Mandel B.R., 2014. The Psychology of advertising: an attempt to understand, or criticism against 


\section{МАТЕРИАЛЫ И СООБЩЕНИЯ}

controversy. Gumanitarnye nauki iobrazovanie v Sibiri, no. 6 (18), pp. 175-180. (in Russian).

Maruseva I.V., 2016. The target of taste: the axioms and structure of art marketing; Graphic design and creative; Advertising art memes; Creative method of creating advertising "Golden Section”. Moscow, Direkt-Media Publ. 305 p. (in Russian).

Meshcheryakova N.V., 2010. The role of expressive means in creating the texts of social advertising. Uchenye zapiski Rossiyskogo gosudarstvennogo sotsialnogo universiteta [RSSU Proceedings], no. 9 (85), pp. 211-214. (in Russian).

Mikheev V.A., 2014. Fundamentals of social partnership: theory and politics. Moscow, Ekzamen Publ. 448 p. (in Russian).

Nikolayshvili G.G., 2008. Social advertising: theory and practice. Regionologiya [Regionology], no. 2, pp. 263-275. (in Russian).

Stepanov E.V., 2007. The features of language and style of social advertising. Vestnik Moskovskogo universiteta. Seriya 10, Zhurnalistika [Vestnik Moskovskogo Universiteta. Series 10. Journalism], no. 4, pp. 24-39. (in Russian).
Ulyanovskiy A., 2014. Mythodesign: commercial and social myths. Moscow, St. Petersburg, Piter Publ. 544 p. (in Russian).

UlyanovskiyA., 2016. Mythology of advertising. Moscow, St. Petersburg, Petropol Publ. 300 p. (in Russian).

Chubay S.A., 2015. Key features of political advertising as a standalone advertising communication. Vestnik Volgogradskogo gosudarstvennogo universiteta. Seriya 2, Yazykoznanie [Science Journal of Volgograd State University. Linguistics], vol. 14, no. 3, pp. 32-39. (in Russian).

Shelkovnikova K.Kh., 2013. Analysis and ways to improve social advertising in the city of Kemerovo. Moscow, LAP Lambert Academic Publ. 108 p. (in Russian).

Boorstin D., 1994. Advertising and American Civilization . Advertising and Society. New York, pp. 24-39.

Cravens D.W. et al., 2007. Cravens D.W., Hills G.E., Woodruff R.B. Marketing Management. Homewood; Illinois, Irwin. 364 p.

Cultip S., Center A., Broom G., 1997. Effective public relations. New Jercy. 243 p.

Goodrum Ch., Dalrymple H., 2010. Advertising in America. The First 200 Years. N.Y., Harry N. Abrams. 477 p.

\section{Information about the Author}

Svetlana A. Chubay, Candidate of Sciences (Philology), Associate Professor, Department of Journalism and Media Communications, Volgograd State University, Prosp. Universitetsky, 100, 400062 Volgograd, Russia, stilvolsu@mail.ru, https://orcid.org/0000-0002-3660-8267

\section{Информация об авторе}

Светлана Анатольевна Чубай, кандидат филологических наук, доцент кафедры журналистики и медиакоммуникаций, Волгоградский государственный университет, просп. Университетский, 100, 400062 г. Волгоград, Россия, stilvolsu@mail.ru, https://orcid.org/0000-0002-3660-8267 